Seção Temática: Balanço do Fundeb

Volume 11 - $2021 \mid$ n. 11

\title{
O Gasto Aluno Ano e o Fundeb: uma análise do financiamento da educação básica dos municípios de Araquari, Florianópolis e Joinville/SC
}

\author{
Jeana Baumgartner Mendonça \\ Kátia Cristina Sommer Schmidt \\ Universidade Federal do Paraná (UFPR), Curitiba/PR - Brasil
}

\section{Resumo}

Este artigo apresenta uma análise do financiamento da educação básica da rede municipal de ensino dos municípios de Araquari, Joinville e Florianópolis/SC, a partir do demonstrativo das receitas e despesas com Manutenção e Desenvolvimento do Ensino disponível no Relatório Resumido da Execução Orçamentária de 2017, elencando os valores disponíveis e o efetivado com gasto em educação e gasto aluno potencial, para então compará-los ao Custo Aluno Qualidade (CAQ) do mesmo ano. A análise dos dados dos três municípios demonstrou a importância do Fundo de Manutenção e Desenvolvimento da Educação Básica e de Valorização dos Profissionais da Educação para o financiamento educacional, sendo esta a principal fonte de recursos desses municípios, além de apresentar características relevantes de cada uma das redes de ensino estudadas.

Palavras-chave: Políticas Educacionais. Financiamento da Educação. Gasto Aluno Ano.

Costs per student/year and Fundeb: an analysis of the basic education funding in the cities of Araquari, Florianópolis and Joinville/SC

\begin{abstract}
This article presents an analysis on the funding for basic education in the municipal education system of the cities of Araquari, Joinville and Florianópolis, SC, based on the statement of revenue and expenses with Maintenance and Development of Education available in the Budget Execution Report of 2017, listing the available values and the amount spent on education and potential cost per student, and compare it with the Cost per Student Quality (CAQ) of the same year. The data analysis of the three cities demonstrated the importance of the Fund for Maintenance and Development of Basic Education and Valorization of Education Professionals for education funding, it being the main source of resources for this cities, in addition to further present the relevants characteristics of each of the studied education networks.
\end{abstract}

Keywords: Educational Policies. Education Funding. Costs per student/year. 
O Gasto Aluno Ano e o Fundeb

\section{Introdução}

Conforme definido na Constituição Federal (CF) de 1988 (BRASIL, 1988) e na Lei de Diretrizes e Bases da Educação Nacional (LDB) - Lei $n^{\circ}$ 9.394/1996 (BRASIL, 1996), são quatro as principais fontes de financiamento da educação no Brasil: I) os impostos próprios e os recursos provenientes de transferências legais; II) a contribuição social do salárioeducação; III) outras contribuições sociais; e IV) receitas de incentivos fiscais; sendo as duas primeiras aquelas de maior representação em termos de volume e regularidade, portanto, as principais fontes de financiamento da educação pública brasileira.

O cálculo realizado para indicar o valor disponível para financiamento educacional tem sido feito por meio das fontes citadas anteriormente, sendo a principal delas: as receitas provenientes dos impostos e transferências, vinculadas à Manutenção e Desenvolvimento do Ensino (MDE), conforme definido constitucionalmente no art. 212, nunca menos de $25 \%$ da receita de impostos municipais, $25 \%$ estaduais e $18 \%$ da União (BRASIL, 1988).

Entende-se que, quando se discorre sobre financiamento da educação e planejamento orçamentário no País, torna-se indispensável abordar o Plano Nacional da Educação (PNE) 2014-2024, aprovado por meio da Lei $n^{0} 13.005 / 2014$, que traz em seu texto inovações quanto ao financiamento educacional, o que implica na reformulação dos planejamentos governamentais para a implementação das metas e estratégias nele previstas. Como exemplo, a meta 20 que trata da ampliação do investimento público em educação, a fim de atingir, no mínimo, o patamar de $7 \%$ do Produto Interno Bruto (PIB) do País no $5^{\circ}$ ano de sua vigência (2019) e o equivalente a $10 \%$ do PIB ao final de sua vigência (2024).

Para o alcance dessa meta foram estabelecidas 12 estratégias no PNE, sendo uma delas a implementação do Custo Aluno Qualidade (CAQ), uma política educacional de financiamento que visa garantir padrão de qualidade que se aproxime a de países mais desenvolvidos, adequando os insumos necessários para garantir a qualidade educacional. Assim, o CAQ deve servir como parâmetro para o financiamento de todas as etapas e modalidades da educação básica pública do País, sendo extremamente importante para a aplicação dessa política (CAMPANHA..., 2018).

Nesse sentido, este artigo estuda o gasto direcionado ao financiamento da educação, entendendo o conceito de gasto conforme Ferraz (2013), a qual discorre que o gasto aluno ano está ligado ao montante que foi utilizado no financiamento da educação e a sua divisão pelo número de matrículas daquele ano, possibilitando conhecer o valor total que foi utilizado para financiar a educação e a relação da política de fundos no contexto municipal, já que o montante vinculado (enviado e recebido) é considerado.

Costa (2000, p. 5) também contribui quando define gasto como "[...] o total do sacrifício financeiro com que a empresa ou instituição arcam para a obtenção de um produto ou serviço". Porém, para a esfera pública, em especial a educação, a autora alerta sobre a transposição das definições, que deve levar em consideração que o gasto da rede pública de determinada esfera de governo deve incorporar "[...] dispêndios não diretamente afetos à escola, mas essenciais para o funcionamento do sistema" (COSTA, 2000, p. 6).

Já o gasto aluno potencial determina o quanto a rede de ensino pode gastar de acordo com a sua receita própria de impostos e transferências, ou seja, o valor do gasto aluno 
potencial possibilita apenas mensurar o valor que a rede pode utilizar para financiar a educação, porém não há garantia de que este valor se efetive (FERRAZ, 2013).

O CAQ usa outra lógica, pois considera o valor necessário para que seja possível oferecer uma educação pública de qualidade, representando a garantia das condições estabelecidas por lei (CARREIRA; PINTO, 2007), desse modo, o cálculo não se pauta nos valores disponíveis, mas sim no necessário.

Diante dessa perspectiva, a discussão desse objeto, sendo ele o gasto aluno ano e o $C A Q$, se mostra importante devido ao contexto vivenciado pela educação brasileira. $A$ efetivação do CAQ estava prevista para o ano de 2017 (três anos após a aprovação do PNE), porém, passado o prazo estabelecido, ainda não foram tomadas as medidas necessárias para sua efetivação, como a implementação do Custo Aluno Qualidade Inicial (CAQi) que se refere aos padrões mínimos de qualidade, previsto como um momento transitório, que visa a disponibilização dos insumos indispensáveis para o ensino e deveria ser implantado até o segundo ano de vigência do PNE (BRASIL, 2014).

Desse modo, parte-se da hipótese de que os municípios não estão atingindo o valor estabelecido no CAQ. Entendendo a importância e também a necessidade da implementação dessa política para a diminuição das desigualdades educacionais historicamente existentes no Brasil foi que se deu a escolha desse tema para discussão.

Em levantamento bibliográfico realizado em meados de setembro do ano de 2018, na plataforma da CAPES, na revista FINEDUCA e no Google Acadêmico, a partir dos descritores "gasto aluno" e "custo aluno qualidade", foi possível encontrar quatro pesquisas que vêm ao encontro da temática deste trabalho.

Dentre os trabalhos encontrados está a dissertação de Ferraz (2013), cujo tema é Panorama do gasto-aluno nas redes estaduais e municipais brasileiras, que em sua discussão apresenta o gasto aluno ano da educação básica brasileira nos anos de 2005, 2007 e 2009 utilizando os dados financeiros do FINBRA (Finanças do Brasil) e do Sistema de Informações sobre Orçamentos Públicos em Educação (SIOPE), disponibilizando a média dos gastos por aluno nas redes de ensino.

Além de demonstrar o panorama do gasto aluno nacional, Ferraz (2013) conceitua o gasto em educação, sendo ele resultado do modelo tributário, da estrutura do financiamento e de como a execução dos recursos financeiros é realizada (planejamento orçamentário e prestação de contas). Também contribui com esta pesquisa quando discorre que "[...] o potencial de se estudar o gasto aluno está principalmente na possibilidade de medir os esforços públicos/políticos em prol da educação" (FERRAZ, 2013, p. 39) evidenciando a importância de conhecer a realidade do financiamento educacional e sua eficiência frente às necessidades educacionais.

O artigo intitulado O gasto aluno-ano no Paraná (Brasil) e a situação de financiamento da educação nas regiões metropolitanas do Estado contribui também com este trabalho, haja vista que as autoras apresentam a média do valor gasto aluno-ano das redes municipais e da rede estadual de ensino do Paraná de 2001 a 2008, a partir dos dados disponibilizados pelo FINBRA (GOUVEIA; SILVA, 2012).

Assim, através da utilização do valor gasto aluno-ano, as autoras apresentaram a dimensão das condições econômicas dos municípios, evidenciando que seu tamanho e a 
O Gasto Aluno Ano e o Fundeb

região em que está localizado pode influenciar indiretamente nos gastos da educação local, ou seja, "[...] municípios com condições econômicas melhores apresentam melhores gastos aluno-ano e municípios com condições economicamente precárias apresentam piores valores de investimento em educação" (GOUVEIA; SILVA, 2012, p. 325).

Outro trabalho importante para esta pesquisa trata-se da tese: Desenvolvimento de um modelo de previsão de custos para planejamento de sistemas públicos de educação básica em condições de qualidade: uma aplicação a municípios de Goiás, que versa sobre a análise dos custos do financiamento da educação brasileira e tem como produto de seu trabalho um Simulador de Custo Aluno Qualidade (SIMCAQ) (ALVES, 2012).

Por fim, o artigo Panoramas do gasto público e da oferta de educação básica na perspectiva da esfera Estadual, que discorre sobre o financiamento da educação das redes estaduais de ensino brasileiro, tendo como referência os anos de 2004, 2006, 2010. Os dados utilizados pela autora para a análise dos gastos estaduais foram retirados da Secretaria do Tesouro Nacional (STN). Por meio das análises advindas sobre o valor do gasto aluno e da distribuição das matrículas entre as redes estaduais e municipais, a autora discute sobre as responsabilidades dos estados frente à oferta e ao financiamento da educação, o qual foi definido através da Emenda Constitucional $(E C) n^{\circ} 14 / 96$, que dividiu a responsabilidade do financiamento da educação entre os entes federados e também criou o Fundo de Manutenção e Desenvolvimento do Ensino Fundamental e Valorização do Magistério (FUNDEF). A leitura possibilita entender que os gastos por aluno nas redes estaduais aumentaram conforme a passagem dos anos, além de observar-se a diminuição na quantidade de matrículas efetuadas nas redes estaduais de ensino (FARENZENA, 2012).

A partir dessa perspectiva, delimitou-se então o problema de pesquisa: qual é o valor do gasto aluno ano dos municípios de Araquari, Florianópolis e Joinville/SC e como se caracteriza o financiamento da educação desses municípios? Com a intenção de compreender se o valor gasto por aluno em tais cidades está próximo ou não do estabelecido pelo $C A Q$, considerando as especificidades municipais.

A escolha dessas cidades para a pesquisa se pautou no interesse da pesquisadora em observar o processo de financiamento municipal no estado de Santa Catarina em contextos distintos em termos populacionais, territoriais e tamanho das redes de ensino, porém semelhantes quando se observa o montante de suas arrecadações, que são altas, diante da realidade populacional de cada uma, o que pode possibilitar a ampliação da análise, levando em consideração as diferenças e semelhanças, conforme pode ser observado na Tabela 1.

Tabela 1 - Apresentação Socioeconômica e Demográfica dos Municípios

\begin{tabular}{llll}
\hline & Araquari & Florianópolis & Joinville \\
\hline Habitantes (CENSO, 2010) & 24210 & 421240 & 515288 \\
PIB per capita (IBGE, 2015) & $\mathrm{R} \$ 85.194,63$ & $\mathrm{R} \$ 39.048,21$ & $\mathrm{R} \$ 45.538,31$ \\
IDH (IBGE, 2010) & 0,703 & 0,847 & 0,809 \\
Taxa escolarização (IBGE, 2010) & $96,00 \%$ & $98,40 \%$ & $97,30 \%$ \\
IDEB 2015 anos iniciais (IBGE, 2015) & 5,9 & 5,7 & 6,9 \\
IDEB 2015 anos finais (IBGE, 2015) & 4,6 & 4,6 & 5,5 \\
\hline
\end{tabular}

Fonte: CENSO (2010); IBGE (2010; 2015). 
O Gasto Aluno Ano e o Fundeb

Em relação aos municípios analisados, pode-se destacar inicialmente as seguintes distinções: a) diferença entre a quantidade de habitantes: a população de Araquari corresponde a $4,8 \%$ a de Joinville e $5,8 \%$ a de Florianópolis; b) PIB per capita: Araquari ultrapassa os demais municípios, obtendo o percentual de $54,16 \%$ à frente de Florianópolis e 46,54\% de Joinville; c) IDH: Florianópolis tem um diferencial de 0,038 no indicador frente a Joinville e 0,144 de Araquari, ou seja, a capital possui melhores condições de renda, saúde e educação, porém, também apresenta semelhanças na renda mensal média da população e na taxa de escolarização. Instiga-se, assim, a comparação da atuação de cada município em relação ao financiamento da educação básica.

Dessa forma, o objetivo geral desta pesquisa é analisar o financiamento da educação básica da rede municipal de ensino nos municípios de Araquari, Joinville e Florianópolis/SC a partir do demonstrativo das receitas e despesas com MDE disponível no Relatório Resumido da Execução Orçamentária de 2017, elencando os valores disponíveis e os efetivados com gasto em educação, assim como o gasto aluno potencial, a fim de compará-los ao CAQ, verificando em que medida os municípios se aproximam ou não do valor estabelecido pelo mesmo; partindo da hipótese de que os municípios não estavam atingindo o valor estabelecido no CAQ.

Tem-se como objetivos específicos: a) verificar os valores de gasto aluno ano e gasto aluno potencial da Educação Básica nos três municípios; b) analisar as diferenças entre as redes de ensino municipais quanto à oferta de vagas; c) examinar o papel do FUNDEB frente à realidade dos municípios e de que forma o fim do fundo poderia afetá-los. d) verificar o quanto os valores do gasto aluno ano dos municípios selecionados se aproximam do CAQ. Dessa forma, discorre-se a seguir sobre como atua o financiamento da educação no Brasil.

\section{Financiamento da Educação}

A educação básica no Brasil foi constitucionalmente estabelecida como obrigatória e gratuita dos quatro aos dezessete anos de idade (BRASIL, 1988), conforme nova redação dada pela $E C \mathrm{n}^{\circ} 59$ de 2009, logo, é direito de todos e dever do Estado a sua garantia.

Diante disso, além de o Estado ter a obrigatoriedade de garantir o direito à educação, a CF (1988) e a LDB (1996) estabelecem como um dos seus princípios a garantia de um padrão mínimo de qualidade, entendido como a variedade e a quantidade mínima de insumos indispensáveis, por aluno, para o seu processo de ensino-aprendizagem (BRASIL, 1996, Art. $4^{\circ}$ ). Assim, desde então a discussão sobre a garantia do direito à educação com um padrão mínimo de qualidade foi ampliada, contudo, inúmeros impasses ocorreram desde esse período, fazendo com que esse padrão mínimo de qualidade não tenha sido efetivado (PINTO, 2006).

Os debates acerca do CAQ iniciaram na Campanha Nacional pelo Direito à Educação em 2002, que tinha como iniciativa elencar parâmetros iniciais para estabelecer uma educação de qualidade, tal ação foi denominada CAQi, que passaria por aperfeiçoamentos para então ser legitimada como CAQ. Assim, posteriormente, essa proposta foi apresentada ao Conselho Nacional de Educação (Parecer $n^{\circ}$ 8/2010), servindo como referência para a elaboração de uma matriz dos padrões mínimos de qualidade para a educação básica (CARDOSO, 2018). O parecer traz em seu texto uma importante reflexão frente às legislações que asseguram o direito à educação, bem como a educação de qualidade, mostrando a 
necessidade de definir quais são os padrões mínimos e os insumos necessários, trazendo o CAQi como uma alternativa para a garantia desse padrão (BRASIL, 2017).

Apesar de homologado, o parecer não foi aprovado pelo Ministério da Educação (MEC). Com a resistência existente para sua aprovação, muitas das soluções de problemas referentes às desigualdades educacionais continuam estagnadas, aguardando a resolução de dificuldades técnicas ou mais debates advindos do MEC (GOUVEIA; SOUZA, 2015). Em 26 de abril de 2019 foi homologado o Parecer $n^{\circ} 3 / 2019$, que arquiva e substitui o Parecer $n^{\circ}$ 8/2010, criado com o propósito de reexaminá-lo (BRASIL, 2019).

Tal discussão foi avançando no meio acadêmico e novas propostas foram desenvolvidas para corrigir as fragilidades existentes no modelo anterior. Dessa forma, a tese de Alves (2012) busca aprimorar o cálculo do CAQ, trazendo parâmetros de cálculo para mensurar, de alguma forma, a qualidade.

Em 2014, com a aprovação do PNE 2014-2024, que também trata da qualidade educacional, essa questão é apontada como uma de suas diretrizes, salientado-se alguns aspectos sobre o financiamento da educação no $3^{\circ}, 4^{\circ}$ e $5^{\circ}$ parágrafo, que demonstram a necessidade da progressão no investimento público nessa área (BRASIL, 2014).

Diante dessa temática, faz-se importante citar que o financiamento da educação brasileira é vinculado aos impostos e transferências recebidas pelos entes federados. Funciona a partir da lógica dos fundos, ou seja, é através do FUNDEB, instituído pela EC $n^{\circ}$ 53 de 2006 e sancionado em 2007 através da Lei $n^{\circ} 11.494$ em substituição ao FUNDEF, garantindo, conforme cita $\mathrm{o}$ art. $2^{\circ}$, que os fundos são destinados à manutenção e ao desenvolvimento da educação básica e à valorização e condigna remuneração dos profissionais do magistério (BRASIL, 2007).

Dessa forma, a referida legislação dispõe que $20 \%$ da receita da vinculação dos impostos e transferências sejam enviados para o fundo, discriminando no art. $3^{\circ}$ as fontes de receitas utilizadas para esse fim (ITCMD, ICMS, IPVA, ITR, entre outros). Além dos recursos pré-estabelecidos, os fundos também podem contar com a complementação da União, no caso dos Estados ou Distrito Federal não alcançarem o valor médio calculado por aluno definido nacionalmente ${ }^{1}$ (BRASIL, 2007). Assim, os recursos do FUNDEB são destinados a toda educação básica, redistribuídos de acordo com um valor médio calculado anualmente por aluno de cada etapa de ensino, para cada ente federado, considerando o número de matrículas de cada rede, a fim de diminuir as desigualdades educacionais (GOUVEIA; SOUZA, 2015).

Nesse aspecto, também contribui o Fundo Nacional da Educação (FNDE), que funciona com o intuito de administrar os recursos advindos do MEC, dentre eles o salário educação e os recursos da MDE, além de "[...] financiar ações voltadas à educação básica, com o intuito de melhorar a qualidade de ensino e a equidade de sua oferta, exercendo assim a função supletiva e redistributiva da União em relação às demais esferas governamentais" (GOUVEIA; POLENA, 2010, p. 02). Dessa forma, gerencia-se os programas referentes à alimentação escolar; banda larga nas escolas; biblioteca na escola; transporte escolar; dinheiro direto na escola; livro didático; plano de desenvolvimento da escola; programa um computador por

\footnotetext{
A respeito do recorte tratado neste artigo, convém esclarecer que o estado de Santa Catarina não necessita
} da complementação da União para atingir o valor médio por aluno. 
O Gasto Aluno Ano e o Fundeb

aluno; PROINFÂNCIA; PROINFO; transporte escolar, entre outros. Destaca-se, a seguir, os recursos utilizados pelos municípios citados nesta pesquisa.

O primeiro deles é o salário educação, trata-se de uma contribuição social estipulada para o financiamento de programas, projetos e ações direcionadas para a educação básica pública, receita adicional prevista no $\S 5^{\circ}$ do art. 212 da CF de 1988. Esses recursos são repartidos em cotas, divididas entre os entes federados, ficando para o estado e municípios o montante de $2 / 3$ dos recursos gerados, distribuído conforme o cálculo do número de matrículas (BRASIL, 1988).

As transferências realizadas pelo Programa Nacional de Apoio ao Transporte Escolar (PNATE) disponibiliza recursos financeiros para o custeio de despesas relacionadas à manutenção, seguros, licenciamentos, impostos e taxas, combustível e demais manutenções e/ou acessórios de veículos necessários para o transporte de alunos da educação básica pública residentes em área rural, podendo também ser usado no pagamento de serviços terceirizados. O valor dessa transferência é calculado a partir do Censo Escolar do ano anterior e da per capita definida pelo FNDE, dados estes disponibilizados no sítio oficial (BRASIL; FNDE, 2017).

Já as transferências realizadas pelo Programa Nacional de Alimentação Escolar (PNAE) oferecem a alimentação e ações de educação alimentar e nutricional aos alunos da educação básica pública. A União é responsável por repassar às instituições de ensino públicas valores financeiros de natureza suplementar, de acordo com cada etapa e modalidade de ensino. Tais valores também são calculados a partir do número de matrículas efetuadas no ano anterior (BRASIL; FNDE, 2017).

Mesmo com a realização dessas estratégias para a garantia do direito educacional, percebe-se que ainda há necessidade de melhorias para que a educação realmente ocorra com a garantia de padrão mínimo de qualidade, ampliando o acesso e as condições de permanência e a melhoria na gestão dos recursos disponíveis (GOUVEIA; SOUZA, 2015).

\section{Educação de Qualidade}

Diante dessa discussão, é válido discorrer acerca do conceito de qualidade, haja vista que este, por vezes, se torna relativo de um indivíduo para o outro (TAPOROSKY, 2017), assim, faz-se necessário estabelecer um parâmetro, de modo que seja possível aproximar-se do que se entende por uma educação de qualidade. Quanto a isso, esta pesquisa concorda com a autora Taporosky, quando relata que a qualidade deve estar ligada ao interesse da maioria, no sentido de proporcionar a emancipação do estudante, tornando-o um sujeito ativo, em que a educação seja considerada essencial para o exercício da cidadania (TAPOROSKY, 2017).

Partindo desse pressuposto da busca por uma educação de qualidade e dos subsídios necessários para alcançá-la, entende-se que a garantia do direito à educação de qualidade necessita do financiamento como um dos mecanismos principais para sua efetivação e, por conseguinte, para o alcance das metas e estratégias dos planos nacional, estaduais e municipais de educação, pois a partir dele será possível a implementação de ações direcionadas à universalização, acesso e permanência dos alunos em uma educação básica de qualidade (FERNANDES; SANTOS, 2017). 
O Gasto Aluno Ano e o Fundeb

Schneider (2013) também contribui quando explica que um dos passos a serem utilizados para alcançar avanços nas condições de qualidade para o aprendizado do aluno são aqueles que perpassam pelo financiamento, pois entende-se que quando há capital existe a possibilidade de a escola realizar seu trabalho com qualidade, já que terá meios para alcançar elementos que agreguem conhecimento e facilidades para o aprendizado.

Ao observar a Constituição Federal (1988), a LDB (1996) e o PNE (2014), é possível perceber que o custo aluno qualidade e a garantia do direito à educação com qualidade estão em pauta quando se visualiza a legislação, contudo, quando o enfoque é a prática e o cotidiano escolar, não se percebe a mesma análise, visto que, dia após dia, as dificuldades enfrentadas nas escolas ganham proporções maiores. Como citado no início do texto, a implementação das metas do PNE e os padrões mínimos de qualidade estão sendo adiadas ao longo dos anos.

Assim, o cumprimento do PNE configura-se como um grande desafio para o governo brasileiro, uma vez que, faltando apenas seis anos para o seu fim, já perdeu alguns dos prazos estabelecidos, necessitando de mais pesquisas para entender as lacunas a serem atendidas para o processo da garantia da educação de qualidade.

\section{Metodologia}

Considerando os objetos definidos para esta pesquisa, quais sejam, o gasto aluno ano e o CAQ para garantia do direito à educação básica de qualidade, a abordagem utilizada será do tipo quantitativo, pois se analisaram dados recolhidos a partir de documentos padrões disponibilizados pelos municípios, sendo utilizada a linguagem matemática para a descrição das conclusões (FONSECA, 2002 apud GERHARDT; SILVEIRA, 2009).

Essa abordagem permitiu não só estabelecer os parâmetros para comparação do gasto aluno ano atual dos três municípios para com o $\mathrm{CAQ}$, mas também analisar o financiamento da educação frente aos desafios empregados pela busca do ensino de qualidade. Quanto ao procedimento metodológico adotado, pretendeu-se empregar, além de percentuais, a análise documental, realizada nos demonstrativos das receitas e despesas com MDE, no RREO de 2017, coletados junto ao SIOPE.

Os dados disponibilizados pelo SIOPE são alimentados e atualizados pelos estados, Distrito Federal e municípios, sendo possível visualizar as receitas de impostos e transferências, receitas enviadas e recebidas via FUNDEB, despesas com quadro do magistério, entre outras informações ligadas às prestações de contas, sendo de responsabilidade do sistema somente o cálculo dos percentuais mínimos aplicados em MDE (FERRAZ, 2013).

Com os dados apresentados pelo SIOPE, o gasto aluno ano da educação básica dos municípios analisados foi calculado a partir do total das despesas em educação subtraídas (se necessário) as despesas com o ensino superior e dividido pelo número de matrículas realizadas em cada município, conforme a fórmula: 


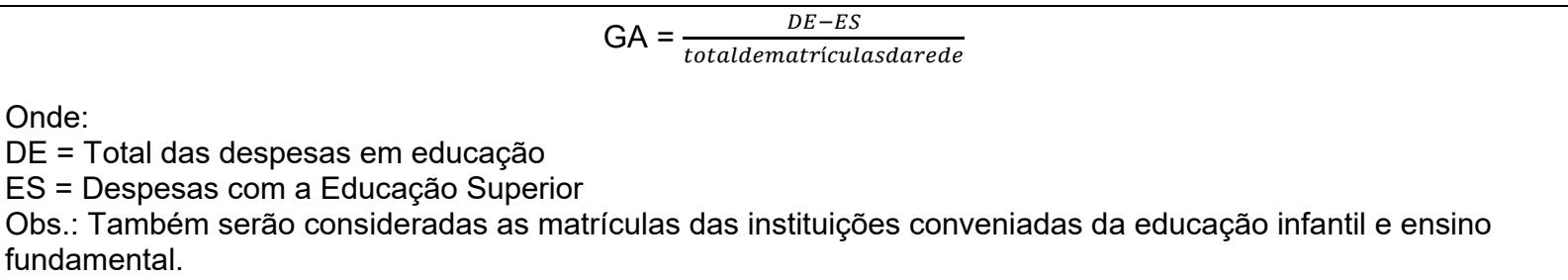

Para a realização do cálculo do gasto aluno potencial, foi utilizado o total das receitas destinadas à educação dividido pelo número de matrículas realizadas em cada município (FERRAZ, 2013), conforme a fórmula:

\[ \text { GAP }=\frac{((I T * 25 \%)-V D F u n d e b)+V R F u n d e b+R A}{\text { totaldematrículasdarede }} \]
Onde:
IT = Total da receita de impostos
VDFundeb = Valor Destinado ao FUNDEB
VRFundeb = Valor Recebido do FUNDEB
RA = Receitas adicionais para financiamento em Educação

A partir do resultado dos valores pesquisados, a próxima etapa da pesquisa consiste na comparação do gasto aluno ano e gasto aluno potencial com o valor do CAQ e, para tanto, foi utilizado o valor médio calculado pelo simulador de custo aluno qualidade (SIMCAQ) desenvolvido por Alves (2012). Trata-se de um software, que realiza a simulação dos custos e do impacto orçamentário do financiamento da educação, a partir de alguns parâmetros de qualidade (insumos, infraestrutura, números de atendimento, faixa etária) para obter o resultado (ALVES, 2012).

Assim, a seguir será possível realizar a discussão frente aos dados encontrados a partir da pesquisa realizada.

\section{Financiamento da Educação dos Municípios de Araquari, Florianópolis e Joinville/SC}

Neste item serão apresentados os dados e resultados obtidos por meio desta pesquisa, bem como a análise realizada através da leitura das informações encontradas. Os resultados e análises serão apresentados a partir da quantidade de matrículas e demonstrativos de receita e despesa para chegar aos valores de gasto aluno ano, gasto aluno potencial e comparação com o valor médio do CAQ.

\section{Matrículas}

As diferenças apontadas nos dados dos municípios, apresentados no início do artigo, também refletem no quantitativo de matrículas das redes, sendo que em 2017 Joinville possuía 126.576 matrículas, número maior do que a capital do estado, Florianópolis, com 100.688, enquanto Araquari apresentava 8.941 matrículas $^{2}$.

O total de matrículas dos municípios demonstra o diferencial da realidade educacional de cada um. O total de matrículas de Araquari representa apenas 7,06\% do total de Joinville, demonstrando uma rede de ensino pequena, diferente de Florianópolis, que se aproxima de Joinville, representando $79,54 \%$ do montante desta. A análise apresentada a seguir considera

\footnotetext{
2 Fonte: Censo Escolar/INEP 2017.
} 
tal contexto, ou seja, foi realizada a partir da visualização de como ocorre a divisão do total das matrículas de cada município por dependência administrativa.

Gráfico 1 - Percentual de Matrículas dos Municípios por Dependência Administrativa (2017)

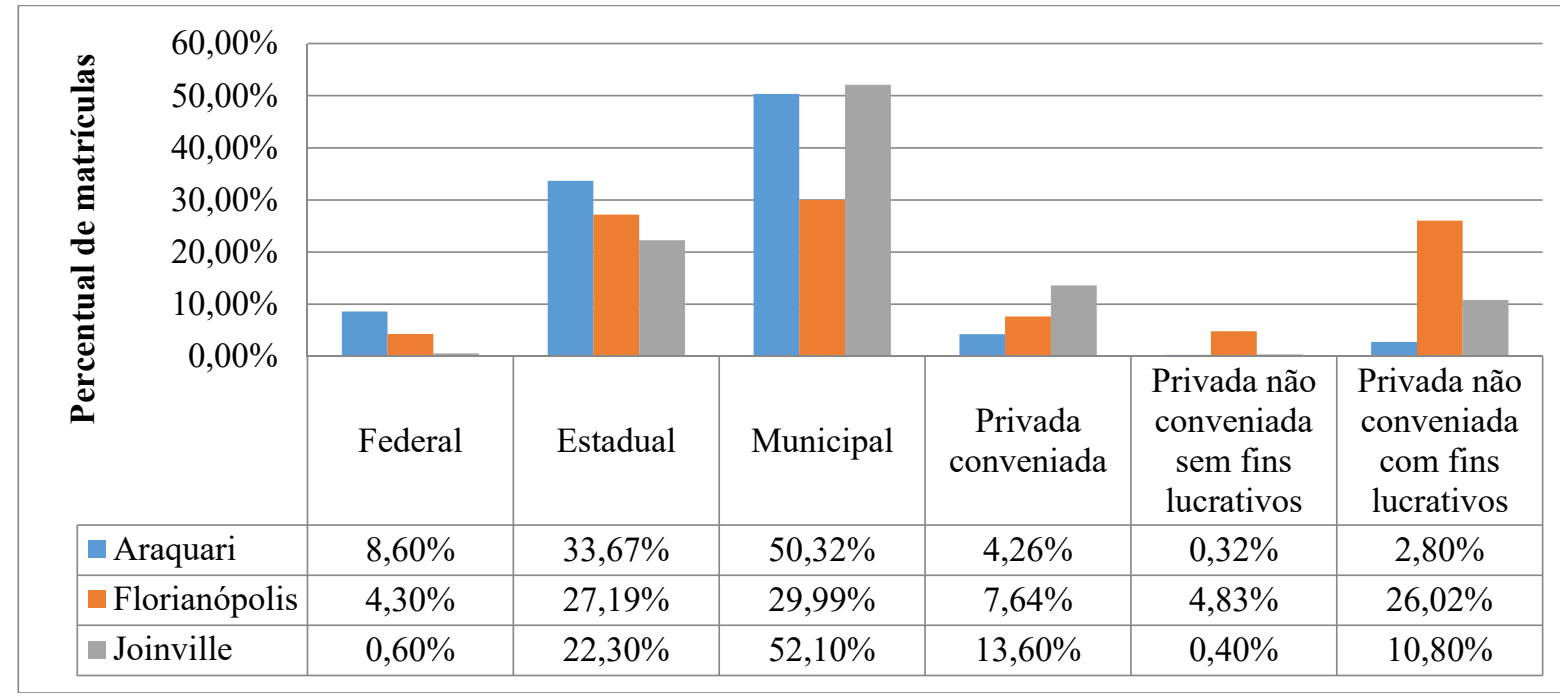

Fonte: Elaborado pela autora com dados do Laboratório de Dados Educacionais (2018) a partir dos dados do Censo Escolar/INEP 2017.

Conforme o Gráfico 1, o município de Joinville possui a maior rede municipal, já que corresponde a $52,10 \%$ do total das matrículas, tendo o percentual mais elevado também na rede conveniada, contando com $13,60 \%$. Araquari também possui o montante mais significativo de suas matrículas na rede municipal, a qual conta com 50,32\% do total das matrículas do município e se destaca no montante referente às matrículas na rede federal de ensino, contando com $8,60 \%$. Florianópolis possui um diferencial frente aos outros dois municípios apresentados, já que o percentual de matrículas da rede municipal e da rede privada está muito próxima, sendo $29,99 \%$ do total de matrículas da rede municipal e $26,02 \%$ da privada não conveniada (que também se aproxima muito ao percentual da rede estadual).

Vale ressaltar que Araquari não atende os anos finais do ensino fundamental, sendo responsabilidade da rede estadual. Em Joinville e Florianópolis a rede estadual também atende aos anos finais, sendo que em Joinville as matrículas do ensino fundamental da rede estadual representam apenas $22,8 \%$ do total de matrículas da rede municipal para a mesma etapa, já na capital os montantes de matrículas são quase equivalentes, pois a rede estadual possui apenas $3,5 \%$ de matrículas a menos que a rede municipal no ensino fundamental.

\section{Financiamento da educação}

$\mathrm{Na}$ tabela a seguir será iniciada a análise frente ao financiamento da educação das cidades aqui apresentadas. Para a análise serão apresentados os dados de receitas e despesas em educação.

As receitas para o financiamento da educação nos municípios foram verificadas pela análise dos dados do SIOPE, a fim de visualizar quais são os valores disponíveis para tal tarefa (Tabela 2). 
O Gasto Aluno Ano e o Fundeb

Tabela 2 - Financiamento da Educação Básica dos Municípios de Araquari, Florianópolis e Joinville - 2017

\begin{tabular}{|c|c|c|c|c|c|c|}
\hline & $\begin{array}{r}\text { Araquari } \\
\text { (em } \mathrm{R} \$ 1.000)\end{array}$ & $\begin{array}{r}\text { Percentual } \\
\text { sobre o total } \\
\text { de receitas } \\
\text { disponíveis }\end{array}$ & $\begin{array}{r}\text { Joinville } \\
\text { (em } \mathrm{R} \$ 1.000)\end{array}$ & $\begin{array}{r}\text { Percentual } \\
\text { sobre o total } \\
\text { de receitas } \\
\text { disponíveis }\end{array}$ & $\begin{array}{r}\text { Florianópolis } \\
\text { (em } \mathrm{R} \$ 1.000)\end{array}$ & $\begin{array}{r}\text { Percentual } \\
\text { sobre o total } \\
\text { de receitas } \\
\text { disponíveis }\end{array}$ \\
\hline $\begin{array}{l}\text { Impostos próprios + } \\
\text { Transferências } \\
\text { Constitucionais legais }\end{array}$ & 72.300 & & 1.064 .648 & & 1.083 .651 & \\
\hline Vinculação MDE (25\%) & 18.075 & & 266.162 & & 270.912 & \\
\hline Destinado ao FUNDEB & 10.898 & & 116.034 & & 68.936 & \\
\hline Recebido FUNDEB & 16.460 & $62,69 \%$ & 261.599 & $57,2 \%$ & 135.285 & $34,84 \%$ \\
\hline Receitas Adicionais & 2.616 & $9,96 \%$ & 45.609 & $9,97 \%$ & 51.002 & $13,13 \%$ \\
\hline Total de receitas disponíveis & 26.253 & & 457.336 & & 388.263 & \\
\hline
\end{tabular}

Fonte: Elaborado pela autora com dados de SIOPE (2017).

Joinville obtém o maior valor de receitas disponíveis para o financiamento da educação, assim, a receita disponível para Araquari corresponde a 5,74\% e Florianópolis $73,74 \%$ em relação a Joinville. Florianópolis também possui um total de receitas disponíveis menor do que Joinville, mesmo tendo um percentual de $1,75 \%$ a mais sobre a vinculação em MDE, já que seu total de impostos próprios e transferências constitucionais legais é mais elevado do que Joinville e Araquari. Assim, Joinville acaba sendo beneficiada com o FUNDEB frente a Florianópolis, devido à quantidade de matrículas, elevando dessa forma sua receita disponível para o financiamento da educação básica.

Com relação às transferências de recursos do FUNDEB, é possível visualizar que as três cidades receberam mais recurso do fundo do que destinam, contudo, Araquari ainda é a mais beneficiada, haja vista que o fundo representa $62,69 \%$ do seu total disponível para financiar a educação, enquanto que para Joinville esse montante representa $57,2 \%$. Florianópolis é o município que menos depende do fundo, porém, ainda sim, recebe mais dele do que destina, já que o montante recebido corresponde a $34,84 \%$ da sua receita total disponível.

Devido a semelhanças e também disparidades frente às receitas adicionais de cada município, foi realizado o demonstrativo de cada receita adicional recebida por eles, a fim de explicitar de onde são os valores recebidos. Assim, observamos que Araquari e Joinville se assemelham com relação ao montante das receitas adicionais, já que o valor disponível para Araquari representa $9,96 \%$ e, para Joinville, $9,97 \%$ do total disponível para o financiamento da educação, porém, Araquari obtém receita da aplicação financeira de outros recursos de impostos e transferências constitucionais legais vinculados ao ensino, diferentemente das demais cidades.

Conforme a Tabela 3, Florianópolis conta com um percentual mais elevado de receitas adicionais e representa $13,13 \%$ do total de receitas disponíveis para a educação, a qual conta também com valores advindos de transferências de convênios e de operações de crédito, diferente dos outros dois municípios, que não a recebem, como pode ser observado a seguir: 
Tabela 3 - Fontes Adicionais para o Financiamento do Ensino - Araquari, Florianópolis e Joinville 2017

\begin{tabular}{lrrr}
\hline \multicolumn{1}{c}{ Receitas adicionais } & Araquari & Joinville & Florianópolis \\
\hline $\begin{array}{l}\text { Receita da aplicação financeira de outros } \\
\text { recursos de impostos vinculados ao ensino } \\
\text { Transferência do Salário-Educação }\end{array}$ & $21.818,70$ & 0,00 & 0,00 \\
Transferências Diretas PNAE & $1.812 .791,76$ & $27.599 .473,83$ & $13.192 .667,55$ \\
Transferências Diretas PNATE & $487.678,00$ & $6.379 .746,00$ & $4.770 .694,00$ \\
Outras Transferências do FNDE & $42.579,81$ & $175.585,49$ & $39.913,50$ \\
Outras Receitas para Financiamento do Ensino & $110.692,60$ & $4.305 .776,65$ & $6.240,03$ \\
Receita de Transferências de Convênios & $141.234,16$ & 0,00 & 0,00 \\
Receita de operações de crédito & 0,00 & 0,00 & $917.231,37$ \\
\hline
\end{tabular}

Fonte: Elaborado pela autora com dados de SIOPE (2017).

A fim de visualizar como os municípios utilizaram os valores disponíveis para o financiamento da educação, foi organizada a Tabela 4 para demonstrar alguns indicadores.

Tabela 4 - Indicadores de Financiamento dos Municípios

\begin{tabular}{lccc}
\hline \multicolumn{1}{c}{ Indicadores } & Araquari & Joinville & Florianópolis \\
\hline $\begin{array}{l}\text { Percentual de aplicação das receitas de impostos e } \\
\text { transferências vinculadas à educação em MDE (mínimo } \\
\text { de 25\% para estados, DF e municípios) }\end{array}$ & $31,70 \%$ & $25,35 \%$ & $27,60 \%$ \\
$\begin{array}{l}\text { Percentual de aplicação do FUNDEB na remuneração } \\
\text { dos profissionais do magistério (mínimo de 60\%) }\end{array}$ & $89,12 \%$ & $72,82 \%$ & $93,29 \%$ \\
$\begin{array}{l}\text { Percentual de despesas correntes em educação em } \\
\text { relação à despesa total em MDE }\end{array}$ & $101,31 \%$ & $98,91 \%$ & $94,37 \%$ \\
$\begin{array}{l}\text { Percentual de investimentos de capital em educação em } \\
\text { relação à despesa total em MDE }\end{array}$ & $1,16 \%$ & $1,08 \%$ & $5,63 \%$ \\
\hline
\end{tabular}

Fonte: Elaborado pela autora com dados do Relatório de Indicadores, SIOPE (2017).

Assim, podemos observar que Araquari aplicou $6,70 \%$ a mais do mínimo de $25 \%$ das receitas de impostos e transferências vinculadas, diferente de Joinville e Florianópolis, que pouco passaram do mínimo garantido constitucionalmente.

Com relação à utilização da receita advinda do FUNDEB, Florianópolis obteve o percentual mais elevado no indicador relacionado à aplicação da verba na remuneração dos profissionais do magistério, utilizando $94,37 \%$ do total dessa receita para esse fim (sendo que a porcentagem mínima é 60\%).

O percentual de despesas correntes em educação em relação à despesa total em MDE entre os três municípios ficou próximo, mostrando que houve despesas destinadas para o custeio da aquisição de bens e materiais de consumo e manutenção necessários ao regular funcionamento da escola (BRASIL; FNDE, 2017). 
O Gasto Aluno Ano e o Fundeb

Araquari e Joinville obtiveram um percentual de 1,16\% e 1,08\% em relação a despesas de capital, ou seja, investiram pouco na aquisição de equipamentos e materiais permanentes para as escolas, que resultam em reposição ou elevação patrimonial, diferentemente de Florianópolis, que aplicou 5,63\% da receita para esse fim (FNDE, 2017).

As despesas para o financiamento da educação nos municípios foram verificadas pela análise dos dados do SIOPE (Tabela 5) a fim de compor o cálculo gasto aluno ano.

Tabela 5 - Total de Despesa em Educação dos Municípios

\begin{tabular}{|c|c|c|c|}
\hline Despesas & Araquari & Joinville & Florianópolis \\
\hline Educação Infantil & $13.460 .503,60$ & $141.488 .955,54$ & $212.945 .329,55$ \\
\hline Ensino Fundamental & $17.536 .110,30$ & $265.781 .962,21$ & $148.361 .298,57$ \\
\hline Ensino Profissional & $146.700,00$ & $59.205,56$ & $320.530,96$ \\
\hline $\begin{array}{l}\text { Total das outras despesas custeadas com receitas } \\
\text { adicionais para financiamento do ensino }\end{array}$ & $3.785 .159,40$ & $21.429 .853,82$ & $30.562 .676,59$ \\
\hline Total geral das despesas com educação & $34.928 .473,30$ & $428.759 .977,13$ & $361.627 .159,08$ \\
\hline
\end{tabular}

Fonte: Elaborado pela autora com dados do Relatório de Indicadores, SIOPE (2017).

Ao iniciar a análise pela educação infantil, verifica-se que Florianópolis declarou maior despesa com essa etapa, sendo que os gastos de Joinville representam $66,4 \%$ e Araquari $6,3 \%$ do total da capital. O mesmo acontece com a educação profissional, em que as despesas da capital ultrapassam em $81,53 \%$ Joinville e $54,23 \%$ Araquari, que por sua vez também ultrapassou Joinville nesse quesito.

Já no ensino fundamental, Joinville apresentou a despesa mais elevada, já que o total de Florianópolis representa $55,82 \%$ do seu montante e Araquari apenas 6,5\%, demonstrando também que essa foi a etapa de ensino com maiores despesas no município de Joinville e Araquari, diferentemente de Florianópolis, que teve a maior despesa na educação infantil.

Outro fator relevante se refere ao total de outras despesas custeadas com receitas adicionais, que estão relacionadas à aplicação financeira de outros recursos de impostos vinculados ao ensino, a contribuição social do salário-educação, as operações de crédito e com outras receitas para financiamento do ensino, mostrando que a capital é quem mais utiliza esse recurso para custear suas despesas, ao contrário de Araquari, em que apenas 12,38\%, do total de Florianópolis, representam suas despesas custeadas pelas receitas adicionais.

\section{Gasto Aluno Potencial, Gasto Aluno Ano e o CAQ}

A partir dos dados apresentados até aqui foi possível obter os valores de gasto aluno potencial e gasto aluno ano relacionados, conforme pode ser visualizado na Tabela 6, além de apresentar-se o valor do CAQ, verificando-se que os valores das três cidades são diferentes, ficando a capital com o valor gasto aluno ano mais elevado, sendo Araquari a que mais se aproxima de Florianópolis, com $29,41 \%$ de gastos a menos. 
Tabela 6 - Valores Gasto Aluno Ano, Gasto Aluno Potencial e Caq (2017)

\begin{tabular}{lrrrr}
\hline & $\begin{array}{r}\text { Número de matrículas } \\
\text { utilizadas para o cálculo }\end{array}$ & $\begin{array}{r}\text { Gasto aluno } \\
\text { potencial }\end{array}$ & $\begin{array}{r}\text { Gasto aluno } \\
\text { ano }\end{array}$ & $\begin{array}{r}\mathrm{CAQ} \\
\text { (valor médio) }\end{array}$ \\
\hline Araquari & 4.654 & $\mathrm{R} \$ 5.641,80$ & $\mathrm{R} \$ 7.505,04$ & $6.194,00$ \\
Florianópolis & 34.336 & $\mathrm{R} \$ 9.822,41$ & $\mathrm{R} \$ 10.532,01$ & \\
Joinville & 76.263 & $\mathrm{R} \$ 5.996,35$ & $\mathrm{R} \$ 5.621,68$ & \\
\hline
\end{tabular}

Fonte: Elaborado pela autora com dados do Relatório de Indicadores, SIOPE (2017).

O valor gasto aluno ano da capital se destaca dos demais, contudo, é necessário ressaltar que Florianópolis, percentualmente, possui a menor rede municipal frente às demais redes apresentadas neste trabalho e sua arrecadação é elevada, além de possuir um montante avantajado de recursos adicionais, que representam $15,12 \%$ da sua receita total.

O que se evidencia é que somente Joinville não atingiu seu potencial de gasto, utilizando $\mathrm{R} \$ 374,67$ a menos do que o pretendido, demonstrando que deixou de executar alguma receita adicional, já que cumpriu o valor de gasto mínimo por aluno definido pelo FUNDEB, que obtém a média de $\mathrm{R} \$ 4.408,00$ (BRASIL, 2018). Já Araquari e Florianópolis obtiveram um percentual maior de gastos do que o pretendido inicialmente, sendo que Araquari o elevou em $33,02 \% \mathrm{e}$ Florianópolis em 7,22\%.

Dessa forma, a partir dos valores obtidos foi possível realizar a comparação com o valor do CAQ, calculado conforme apresentado na metodologia da pesquisa de Alves (2012). Percebe-se, assim, que dentre os três municípios o único que não alcançou o valor calculado para o CAQ foi Joinville, onde o seu valor gasto aluno ano equivale a $90 \%$ do valor médio do $\mathrm{CAQ}$. Os demais municípios pesquisados obtiveram o valor gasto aluno ano acima do valor médio do CAQ, Araquari em $21,16 \%$ e Florianópolis em $70 \%$ a mais.

Outro dado importante que se pode obter pelo SIMCAQ são os valores médios do gasto aluno dos municípios brasileiros. A Tabela 7 apresenta os valores médios de gasto aluno ano, assim como a faixa em que os municípios analisados se encontram no cenário nacional.

Tabela 7 - Análise Estatística do Gasto Aluno Ano dos Municípios Brasileiros, 2017

\begin{tabular}{cc}
\hline Gasto aluno ano & Valor (em reais) \\
\hline Média & $5.876,00$ \\
Menor & 900,00 \\
$20 \%$ menores & $4.179,00$ \\
Mediana & $5.473,00$ \\
$20 \%$ maiores & $7.199,00$ \\
Maior & $47.408,00$ \\
\hline Municípios analisados & 5.542 \\
\hline
\end{tabular}

Fonte: SIMCAQ (2017) a partir dos dados do Siope, Fibra e Censo Escolar/2017.

Dessa forma, é possível visualizar que Araquari encontra-se entre os $20 \%$ maiores valores de gasto aluno ano, assim como Florianópolis, apesar deste ser $65 \%$ maior do que o valor de Araquari. Contudo, Joinville encontra-se acima do valor gasto aluno ano considerado nos $20 \%$ menores, porém se encontra abaixo da mediana, que é $R \$ 5.473,00$, estando também mais distante da média do valor gasto por aluno dentre todos os municípios. 
O Gasto Aluno Ano e o Fundeb

\section{Considerações Finais}

Este artigo teve como objetivo analisar o financiamento da educação básica da rede municipal de ensino nos municípios de Araquari, Joinville e Florianópolis/SC, a partir do RREO de 2017, elencando os valores disponíveis e os efetivados com gasto em educação, assim como o gasto aluno potencial, e compará-los ao CAQ, verificando em que medida os municípios se aproximam ou não do valor estabelecido pelo mesmo.

Desse modo, partiu-se da hipótese de que os municípios não estavam atingindo o valor estabelecido no CAQ, haja vista que essa metodologia não fora aplicada conforme programado pelo PNE 2014-2024 e que a base utilizada pelos municípios para calcular o valor de gasto aluno ano era a apresentada pelo FUNDEB anualmente, a fim de realizar os repasses do fundo.

Após calcular o valor gasto aluno ano e o gasto aluno potencial, como elencado no primeiro objetivo específico, foi possível verificar que os valores obtidos são destoantes, já que Araquari e Florianópolis se destacam obtendo um valor superior ao definido pelo $C A Q$, e Joinville, que além de ter um montante inferior, também não atingiu seu gasto potencial. De modo que a hipótese da pesquisa não se efetiva por completo nos municípios analisados, sendo que todos os valores obtidos ultrapassam o valor de gasto mínimo calculado pelo FUNDEB.

Ao analisar as diferenças entre as redes municipais, de acordo com o segundo objetivo específico, verificou-se a quantidade de matrículas, a divisão da responsabilidade entre os demais entes federados e também a quantidade de escolas que caracterizam suas distinções, pois Araquari e Joinville percentualmente possuem a rede municipal de ensino maior que a de Florianópolis, porém Araquari divide a responsabilidade do atendimento com a rede estadual, já que os anos finais do ensino fundamental do município são atendidos totalmente pela rede estadual. Florianópolis possui um percentual muito próximo no que se refere às matrículas na rede municipal e na rede estadual de ensino, além de ser a cidade com o maior número de matrículas na rede privada não conveniada com fins lucrativos. Já Joinville possui a maior rede municipal de ensino, dentre as três cidades pesquisadas, e se destaca também no que diz respeito às matrículas nas redes conveniadas, evidenciando que ainda não consegue atender em sua totalidade a educação básica, já que necessita realizar convênio com a rede privada.

Com relação ao terceiro objetivo específico, examinar o papel do FUNDEB frente à realidade dos municípios e de que forma o fim do fundo poderia afetá-los, foi possível verificar que os três municípios são dependentes do fundo. Pois todos recebem mais recurso do que enviam, destacando-se Araquari e Joinville, onde o valor recebido do fundo representa mais do que a metade do valor disponível para o financiamento da educação de suas redes. Evidencia-se que o fim do fundo iria afetá-los, já que não teriam como financiar a educação dos seus municípios, pois faltariam recursos para garantir os padrões mínimos de qualidade, bem como o pagamento dos profissionais da educação.

$\mathrm{E}$ ao verificar-se o quarto objetivo deste estudo, os valores de gasto aluno ano e gasto aluno potencial da educação básica nas três cidades e o quanto os valores se aproximam do $C A Q$, foi possível perceber que o valor gasto aluno ano realizado pelos três municípios não 
O Gasto Aluno Ano e o Fundeb

se aproxima entre si, sendo que Araquari e Florianópolis ultrapassam o valor do $\mathrm{CAQ}$, ficando somente Joinville abaixo dessa média.

Dessa forma, este trabalho abre precedentes para novas pesquisas, como um estudo de caso referente à rede municipal de Joinville, visando verificar os motivos que levam o município a não atingir o valor do CAQ; a busca pelo valor gasto aluno da rede de ensino estadual de Santa Catarina, bem como a dos demais municípios, para analisar o financiamento da educação do estado e também verificar se outros municípios se assemelham a Joinville ou se possuem realidades ainda mais distintas aos três municípios apresentados nesta pesquisa, além de poder-se visualizar a relação do estado/municípios com a política do FUNDEB.

\section{Referências}

ALVES, T. Desenvolvimento de um modelo de previsão de custos para planejamento de sistemas públicos de educação básica em condições de qualidade: uma aplicação a municípios de Goiás. 2012. Tese (Doutorado em Ciências) - Universidade de São Paulo, São Paulo, 2012. Disponível em: <http://www.teses.usp.br/teses/disponiveis/12/12139/tde13082012-165657/>. Acesso em: 15 jun. 2018.

BRASIL. Constituição da República Federativa do Brasil. Diário Oficial da União, Brasília, 1988. Disponível em: <http://www.planalto.gov.br/ccivil_03/constituicao/constituicao.htm>. Acesso em: 11 jun. 2018.

BRASIL. Ministério da Educação. Gabinete do Ministro. Portaria $n^{\circ} 7$, de 28 de dezembro de 2018. Estabelece os parâmetros operacionais para o Fundo de Manutenção e Desenvolvimento da Educação Básica e de Valorização dos Profissionais da Educação FUNDEB, no exercício de 2019. Diário Oficial da União, Brasília, DF, 31 dez. 1999. p. 55.

BRASIL. Ministério da Educação. Parecer CNE/CEB n. 8/2010. Estabelece normas para aplicação do inciso IX do artigo $4 .^{\circ}$ da Lei n. ${ }^{\circ} 9.394 / 96$ (LDB), que trata dos padrões mínimos de qualidade de ensino para a Educação Básica Pública. Brasília: MEC, 2010.

BRASIL. Lei n 13.005, de 25 de junho de 2014. Aprova o Plano Nacional de Educação - PNE e dá outras providências. Diário Oficial da União, Brasília, 2014. Disponível em <http://www. planalto.gov.br/ccivil_03/_ato2011-2014/2014/lei/l13005.htm>. Acesso em: 11 jun. 2018.

BRASIL. Ministério da Educação. Parecer CNE/CEB n. ${ }^{\circ}$ 3/2019. Reexame do Parecer CNE/CEB no 8/2010, que estabelece normas para a aplicação do inciso IX do artigo $4^{\circ}$ da Lei no 9.394/96 (LDB), que trata dos padrões mínimos de qualidade de ensino para a Educação Básica pública. Brasília: MEC, 2019.

CAMPANHA Nacional Pelo Direito À Educação. CAQi e o CAQ no PNE: Quanto custa a educação pública de qualidade no Brasil? São Paulo: Campanha Nacional pelo Direito à Educação, 2018. Disponível em: <http://www.custoalunoqualidade.org.br/pdf/quanto-custa-aeducacao-publica-de-qualidade-no-brasil.pdf>. Acesso em: 11 jun. 2018

CARDOSO, J. A. O custo-aluno nas unidades de uma rede municipal de educação básica. 2018. Dissertação (Mestrado em Educação) - Universidade Federal do Paraná, Curitiba, 2018. Disponível em: <http://www.prppg.ufpr.br/siga/visitante/trabalhoConclusao 
O Gasto Aluno Ano e o Fundeb

WS idpessoal $=42599 \&$ idprograma $=40001016001$ P0 \&anobase $=2018 \& i d t c=1310>$. Acesso em: 13 set. 2018.

CARREIRA, D.; PINTO, J. M. R. Custo Aluno-Qualidade inicial: rumo à educação pública de qualidade no Brasil. São Paulo: Campanha Nacional pela Educação, 2007. Disponível em: $<$ <ttp://www.educadores.diaadia.pr.gov.br/arquivos/File/pdf/qualidade_aluno.pdf>. Acesso em: 17 jun. 2018.

COSTA, V. L. C. Considerações sobre estudos de gasto e custo aluno. Brasília: MEC, 2000. Disponível em: <http://portal.mec.gov.br/setec/arquivos/pdf/Custo\%20e\%20gasto\%2 0aluno-1.pdf>. Acesso em: 08 out. 2018.

CURY, C. R. J. A educação básica como direito. Cadernos de Pesquisa, São Paulo, v. 38, n. 134 , p. 293-303, 2008. Disponível em: <http://www.scielo.br/scielo.php?pid=S010015742008000200002\&script=sci_abstract\&tIng=pt>. Acesso em: 11 out. 2017.

FARENZENA, N. A política de financiamento da educação básica: rumos da legislação brasileira. Porto Alegre: Editora da UFRGS, 2006.

FARENZENA, N. Panoramas do gasto público e da oferta de educação básica na perspectiva da esfera Estadual. Fineduca - Revista de Financiamento da Educação, Porto Alegre, v. 2, n. 6, 2012. Disponível em: <https://seer.ufrgs.br/fineduca/article/view/41124>. Acesso em: 08 out. 2018.

FERNANDES, M. D. E.; SANTOS, M. F. M. A meta 20 do PNE 2014-2024: Compromissos e desafios para o contexto do financiamento educacional. Fineduca - Revista de Financiamento da Educação, Porto Alegre, v. 7, n. 3, 2017.

FERRAZ, J. P. Panorama do gasto-aluno nas redes estaduais e municipais brasileiras. 2013. Dissertação (Mestrado em Educação) - Universidade Federal do Paraná, Curitiba, 2013. Disponível em: <http://www.ppge.ufpr.br/teses/M13_Jokasta\%20Pires\%20Vieira\% 20Ferraz.pdf>. Acesso em: 8 out. 2018.

GERHARDT, T. E.; SILVEIRA, D. T. Métodos de pesquisa. Universidade Aberta do Brasil. Porto Alegre: UFRGS, 2009.

GOUVEIA, A. B.; POLENA, A. Recursos do FNDE e sua importância nos municípios da Região Metropolitana de Curitiba. Revista Eletrônica Política e Gestão Educacional, Araraquara, v. 9, 2010. Disponível em: <https://periodicos.fclar.unesp.br/rpge/article/view/ 9282/6159>. Acesso em: 14 jan. 2019.

GOUVEIA, A. B.; SILVA, I. F. O gasto aluno-ano no Paraná (Brasil) e a situação de financiamento da educação nas regiões metropolitanas do Estado. Perspectiva, Florianópolis, v. 30, n. 1, 2012.

GOUVEIA, A. B.; SOUZA, A. R. A política de fundos em perspectiva histórica: mudanças de concepção da política na transição Fundef e Fundeb. Em Aberto, Brasília, v. 28, p. 45-65, 2015.

IBGE. Instituto Brasileiro de Geografia e Estatística. Cidades, Joinville. Rio de Janeiro, 2010. Disponível em: <https://cidades.ibge.gov.br/xtras/temas.php?lang=\&codmun=420910\&idte ma=16\&search=||s\%EDntese-das-informa\%E7\%F5es>. Acesso em: 11 nov. 2018. 
O Gasto Aluno Ano e o Fundeb

PINTO, M. R. Uma proposta de custo-aluno-qualidade na educação básica. Revista Brasileira de Política e Administração da Educação, Goiânia, v. 22, p. 197-227, 2006.

SCHNEIDER, G. Relação Gasto aluno, condições de qualidade e IDEB nos municípios paranaenses. In: SIMPÓSIO BRASILEIRO DE POLÍTICA E ADMINISTRAÇÃO DA EDUCAÇÃO, 2013, Recife. Cadernos ANPAE. Timbaúba: Espaço Livre, 2013. v. 17.

TAPOROSKY, B. C. H. O controle judicial da qualidade da oferta da educação infantil: um estudo das ações coletivas nos tribunais de justiça do Brasil (2005-2016). 2017. Dissertação (Mestrado em Educação) - Universidade Federal do Paraná, Curitiba, 2017. Disponível em: <https://acervodigital.ufpr.br/bitstream/handle/1884/49339/R\%20-\%20D\%20\%20BARBARA\%20CRISTINA\%20HANAUER\%20TAPOROSKY.pdf?sequence=1\&isAllowed $=\mathrm{y}>$. Acesso em: 13 set. 2018.

Jeana Baumgartner Mendonça é especialista em Políticas Educacionais pela Universidade Federal do Paraná (UFPR) (2019), graduada em Pedagogia pela Associação Catarinense de Ensino (2015). Atualmente atua como professora de educação infantil da Prefeitura Municipal de Araquari. Experiência na área de Educação com o público adolescente em situação de vulnerabilidade social e educação infantil.

ORCID: http://orcid.org/0000-0002-2456-878X

E-mail: jeanabaumg@hotmail.com

Kátia Cristina Sommer Schmidt é mestre em Educação pelo Programa de Pós-Graduação em Educação da Universidade Federal do Paraná (UFPR) - Linha de Pesquisa em Políticas Educacionais (2019). Licenciada em Pedagogia pela Universidade da Região de Joinville UNIVILLE (2016). Atualmente é assistente de direção na Escola Municipal Vicente Vieira da rede municipal de ensino de Garuva/SC, onde já atuou como professora de anos iniciais do ensino fundamental (2012-2016) e secretária escolar (2017-2019). Tem experiência na área de educação, atuando principalmente nos seguintes temas: educação e infância, direito à educação, políticas educacionais.

ORCID: http://orcid.org/0000-0001-5815-8546

E-mail: katiacschmidt@gmail.com 


\section{Editores do volume 11}

Márcia Aparecida Jacomini - Universidade Federal de São Paulo, Brasil

José Marcelino de Rezende Pinto - Universidade de São Paulo, Brasil

\section{Comitê Editorial}

Nalú Farenzena - Universidade Federal do Rio Grande do Sul, Brasil

Juca Gil - Universidade Federal do Rio Grande do Sul, Brasil

Theresa Adrião - Universidade Estadual de Campinas, Brasil

Ângelo Ricardo de Souza - Universidade Federal do Paraná, Brasil

\section{Conselho Editorial}

\section{Alejandro Morduchowicz}

Universidad Pedagógica, Provincia de Buenos Aires, Argentina

Andréa Barbosa Gouveia

Universidade Federal do Paraná, Brasil

Fernanda Saforcada

Universidade de Buenos Aires, Argentina

Jacques Velloso

Universidade de Brasília, Brasil

João Monlevade

Senado Federal, Brasil

Jorge Abrahão de Castro

Instituto de Pesquisa Econômica Aplicada / IPEA, Brasil

Lisete Regina Gomes Arelaro

Universidade de São Paulo, Brasil

Luis Carlos Sales

Universidade Federal do Piauí, Brasil

Luiz de Sousa Junior

Universidade Federal da Paraíba, Brasil

Luiz Fernandes Dourado

Universidade Federal de Goiás, Brasil

Magna França

Universidade Federal do Rio Grande do Norte, Brasil

Marcos Edgar Bassi

Universidade Federal de Santa Catarina, Brasil

Maria Angélica Pedra Minhoto

Universidade Federal de São Paulo, Brasil

Maria Beatriz Luce

Universidade Federal do Rio Grande do Sul, Brasil

Maria Dilnéia Espíndola Fernandes

Universidade Federal de Mato Grosso do Sul, Brasil

Nelson Cardoso do Amaral

Universidade Federal de Goiás, Brasil

Nicholas Davies

Universidade Federal Fluminense, Brasil

Robert E. Verhine

Universidade Federal da Bahia, Brasil

Romualdo Portela de Oliveira

Universidade de São Paulo, Brasil

Rosana Gemaque Rolim

Universidade Federal do Pará, Brasil

Rubens Barbosa de Camargo

Universidade de São Paulo, Brasil

Theresa Adrião

Universidade Estadual de Campinas, Brasil

Tristan McCowan

University of London, Reino Unido

Vera Jacob

Universidade Federal do Pará, Brasil

Vera Peroni

Universidade Federal do Rio Grande do Sul, Brasil

Vitor Henrique Paro

Universidade de São Paulo, Brasil

\section{Equipe editorial}

Apoio ao Comitê Editorial: Caio Cabral da Silva

Diagramação, Revisão de português e normalização: Edson Leonel de Oliveira

Revisão de inglês: Sabrina Ferreira

Fineduca - Revista de Financiamento da Educação

Associação Nacional de Pesquisa em

Financiamento da Educação

e-mail: revista.fineduca@gmail.com | site: http://seer.ufrgs.br/fineduca 